\title{
Aníbal Quijano: orígenes de sus luchas contra el poder*
}

\begin{abstract}
RESUMEN
Presenta la vida y la obra académica de un pensador y teórico social peruano y latinoamericano sanmarquino. Muestra los momentos más importantes de la vida y el trabajo en el campo de la sociología y la construcción de sus propuestas teóricas sobre la modernidad y la colonialidad del poder. Se incluyen fotos inéditas de la vida social y familiar de un pensador que se enfrentó en su vida política al modelo cultural civilizatorio eurocentrista y al neoliberalismo global.
\end{abstract}

Palabras clave: Sociología; poder; capitalismo; Perú; Yungay.

\section{Anibal Quijano: origins of his struggles against power}

\begin{abstract}
This paper presents the life and academic work of a Peruvian (Latin American) thinker and social theorist from San Marcos (UNMSM). It shows significant moments of his life, research work in sociology, and production of theoretical proposals on modernity and coloniality of power. Includes unpublished photos about the social and family life of a thinker whose political experience faced the civilizing Eurocentric cultural model and global neoliberalism.
\end{abstract}

KeYwords: Sociology; power; capitalism; Peru; Yungay. 
$\mathbf{E}$ $\mathrm{n}$ las páginas que siguen trataremos de referirnos de manera apretada a algunas de las fases y momentos en la trayectoria intelectual de un socialista revolucionario, anticapitalista y antiburgués como lo fue Aníbal Quijano. Esperamos identificar ciertos factores o fragmentos de estos que sin duda jugaron papel significativo en el proceso de su evolución ideológica y política.

Aníbal Quijano Obregón nació el 17 de noviembre de 1930 en el distrito de Yanama, provincia de Yungay, departamento de Ancash, como consta en su partida de nacimiento expedida por la respectiva municipalidad distrital. Sus padres fueron don Marcial Quijano Vega y dońa Alfonsa Obregón Agama, ambos jóvenes veinteańeros en esos tiempos, él maestro de escuela como "preceptor diplomado» y más tarde «normalista» y ella dedicada básicamente a las labores domésticas. Había que compartir responsabilidades en el cuidado del recién nacido y de sus dos hermanas mayores pero aún niñas que se llamaban Luzmila y Amelia. Los tres hijos crecieron en la casa familiar especialmente ante la figura protectora del abuelo materno don Liborio Obregón Sáenz, empeñado en su trabajo artesanal como tejedor de alfombras, ocupando con frecuencia parte del amplio corredor de la casa, aunque preferentemente dedicado a sus principales tareas como eran la crianza de animales y las actividades agrícolas en los diferentes pisos ecológicos de la zona; en la casa vecina, apenas separada por un huerto, vivían los abuelos y familiares paternos; muchas o casi todas las familias del pueblo eran pequeños propietarios de chacras dispersas en aquellos pisos en los que era posible cultivar desde tubérculos y tarhui en las alturas hasta cereales en las partes bajas. Cada uno de los niños de la casa, como todos los del pueblo, conforme alcanzaban a cumplir los seis o siete años de edad, hacían su ingreso a la escuela de mujeres o a la de varones del lugar, respectivamente; la mayoría de alumnos hasta culminar el quinto ańo de primaria y los demás, unos pocos, sólo hasta el tercer ańo. Estos últimos, luego eran llevados a la ciudad de Yungay, capital de la provincia, para proseguir sus estudios de cuarto y quinto año de primaria y después ingresar al Colegio Nacional Santa Inés para cursar sus estudios de secundaria. En este sentido, es probable que sus tres primeros años de primaria, Aníbal los cursara en 1938-1939-1940 en la escuela de Yanama cuyo director era precisamente su padre don Marcial;

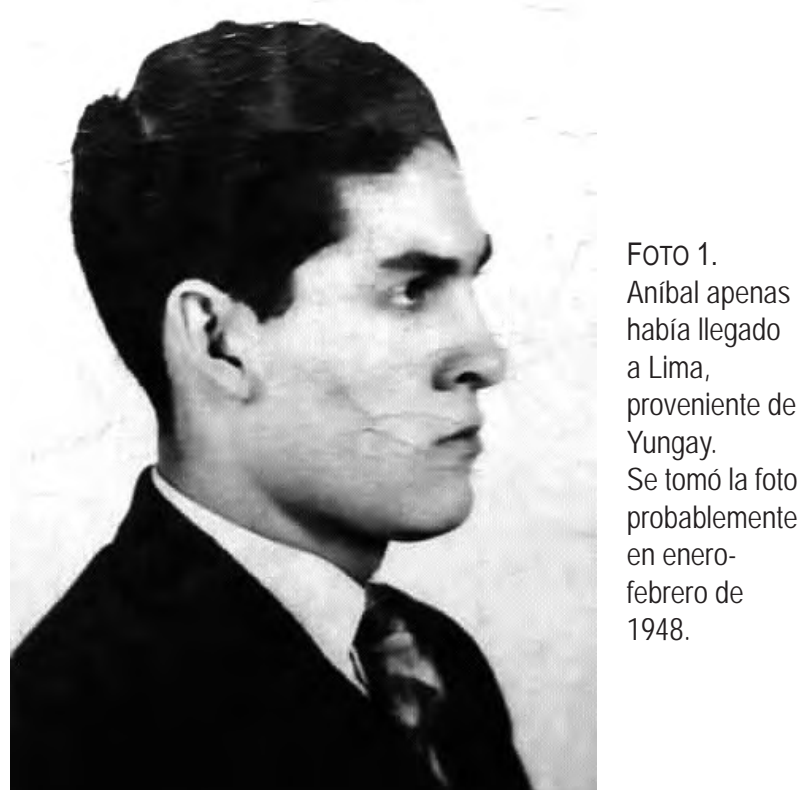

allí encontró que muchos de sus compañeros de estudios eran hijos de los campesinos quechuahablantes o «indios» y que varios de ellos eran conocidos amigos suyos debido a sus cotidianas andanzas infantiles en la calle o en lugares vecinos; el quechua era la lengua dominante en toda la zona de Conchucos extendida, a su vez, a otras zonas del Perú central y en gran medida vigente hasta hoy. El director y los demás profesores, desde el primer día impartían las clases en quechua y español; el trabajo docente, con participación activa de los propios alumnos, consistía en la traducción oral del idioma oficial al quechua y viceversa; igual cosa ocurría con los textos oficiales de lectura y en todos los aspectos de la vida escolar. Con el tiempo, todos los escolares y sus profesores manejaban correcta y fluidamente las dos lenguas y eran bilingües. Como consecuencia, sus conocimientos de las cosas en general revelaban una mayor asimilación del pensamiento andino o "indígena». Esta fase de la vida estudiantil fue sin duda bastante significativa para todos los alumnos y especialmente para el propio Aníbal, quien vivía experiencias simultáneas respecto de sus relaciones con el campesinado indígena y los niños indios debido a que su padre, con su reconocida autoridad intelectual, era públicamente un serio defensor de la «raza» indígena, identificado con sus protestas y reclamos frente al gamonalismo de la región y solidario con ellos ante la explotación y dominación de las que eran víctimas. Al mismo tiempo, 
tica antidictatorial y antiautoritaria en su hijo; como muchos maestros peruanos de su generación, desde los candentes años 30 había sido atento lector de los escritos de Haya de la Torre y José Carlos Mariátegui quienes, a su vez, habían sido protagonistas de importantes debates teóricos y políticos particularmente entre 1927 y 1929 hechos que al mismo tiempo llevaron a una ruptura histórica y a la conformación de dos significativas corrientes ideológico-políticas en el ancho campo popular peruano: por un lado, la corriente democrático-nacional expresada en el Apra y, por otro, la corriente revolucionaria socialista expresada en el Partido Socialista. Aníbal había descubierto tempranamente que entre los papeles y algunos libros de don Marcial estaban guardados los 7 ensayos de interpretación de la realidad peruana de Mariátegui y algunos ejemplares de la revista Amauta de la cual este mismo escritor había sido fundador y director ${ }^{3}$. Los 7 ensayos, con el enfoque y visión fundamentalmente marxistas de su autor, contenía escritos críticos y trascendentales que iluminaban y esclarecían los problemas históricos de la sociedad peruana, tales como el problema del indio, el problema de la tierra, el proceso de la instrucción pública, el proceso de la literatura presentando en especial las figuras de escritores como don Ricardo Palma y don Manuel González Prada, Valdelomar, Vallejo, etc. A su vez, Amauta era una revista de debate y definición ideológica. En la biblioteca del colegio o de otras instituciones públicas, quizás no eran hallables estas obras pero sí muchas otras como las de historia universal, novelas clásicas o tomos de enciclopedias, suficientes como para ser devoradas por la juventud estudiosa llena de inquietudes. En medio de esta realidad provinciana y regional el estudiante Aníbal Quijano ocupó el primer puesto en todos y cada uno de los años de su vida colegial; al egresar como integrante de la promoción de 1947, en el acto público de clausura el Colegio Santa Inés lo premió haciéndole entrega de la entonces afamada novela La cabaña del Tío Tom, de la escritora norteamericana Harriet Beecher Stowe, que hablaba del negro y de las condiciones de la esclavitud negra ${ }^{4}$. La lectura de dicha obra, habría

3 Prólogo de Aníbal Quijano al libro de Claudio Augusto Alba Herrera, Influencia de José Carlos Mariátegui en Huarás-Ancash, Huarás: Waraq Qoyllur, 2016.

4 Novela cuya primera edición era de 1852 y que hasta fines del aquel siglo xIx había tenido innumerables ediciones en diferentes idiomas acentuado los sueños e intenciones de Aníbal por estudiar e investigar más adelante la historia del negro. Lo intentó hacer más tarde, consultando infinidad de documentos coloniales, en los años 50, cuando era estudiante universitario y, a la vez, empleado del Archivo General de la Nación.

Aníbal Quijano llegó a Lima a comienzos de 1948. Fue recibido en una modesta vivienda en la Avenida República Dominicana 351-inteior 1, frente al mercado del hoy distrito de Jesús María, donde vivía don Félix Quijano Vega, hermano menor de su padre, Guardia Civil y activo militante aprista. Aquel año era de una intensa agitación política en Lima y en todo el país encontrándose enfrentados, por un lado, el opaco e inepto gobierno de Bustamante y Rivero y, por otro lado, el Apra que para no pocos de sus seguidores y adversarios aún conservaba su aureola de movimiento revolucionario antioligárquico y antiimperialista. Sus primeras visitas fueron a la Casa del Pueblo de la Av. Alfonso Ugarte. Aníbal llegaba allí como dirigente de la JAP de Yungay. Al poco tiempo, ingresó a la Facultad de Medicina de San Fernando de la Universidad de San Marcos. Como militante aprista, se incorporó de inmediato a las actividades y tareas del partido. Ante las sistemáticas críticas y demandas políticas del Apra, la contraofensiva del gobierno conservador era cada vez más agresiva. En aquellas circunstancias de agudización de los conflictos había ocurrido la sublevación aprista del 3 de octubre con participación protagónica de la Armada peruana y sectores del Apra la misma que fuera derrotada tanto por el Ejército y la Aviación como por las contradicciones internas entre los dirigentes, los diferentes escalones y las bases partidarias apristas. Comenzaron entonces las venganzas y persecuciones a los líderes y cuadros de dicho partido. A través del Ministerio de Educación fue impartida la orden para que Luis Alberto Sánchez no pudiera continuar siendo rector de la Universidad de San Marcos, lo desestabilizaron y arrinconaron con maniobras legaloides y burocráticas, lo obligaron a renunciar a su cargo y salir nuevamente al destierro. Una vez más el

hasta alcanzar los tres millones de ejemplares, acicateadas en gran medida por la guerra civil norteamericana (1861-1865). Esta tendencia expansiva de su difusión se había mantenido durante la primera mitad del siglo xx y, en especial, en las vísperas de cumplirse el primer centenario de su primera edición; la principal editora y distribuidora en América Latina era la editorial TOR de Buenos Aires, una de cuyas prioridades era la publicación de novelas clásicas. 


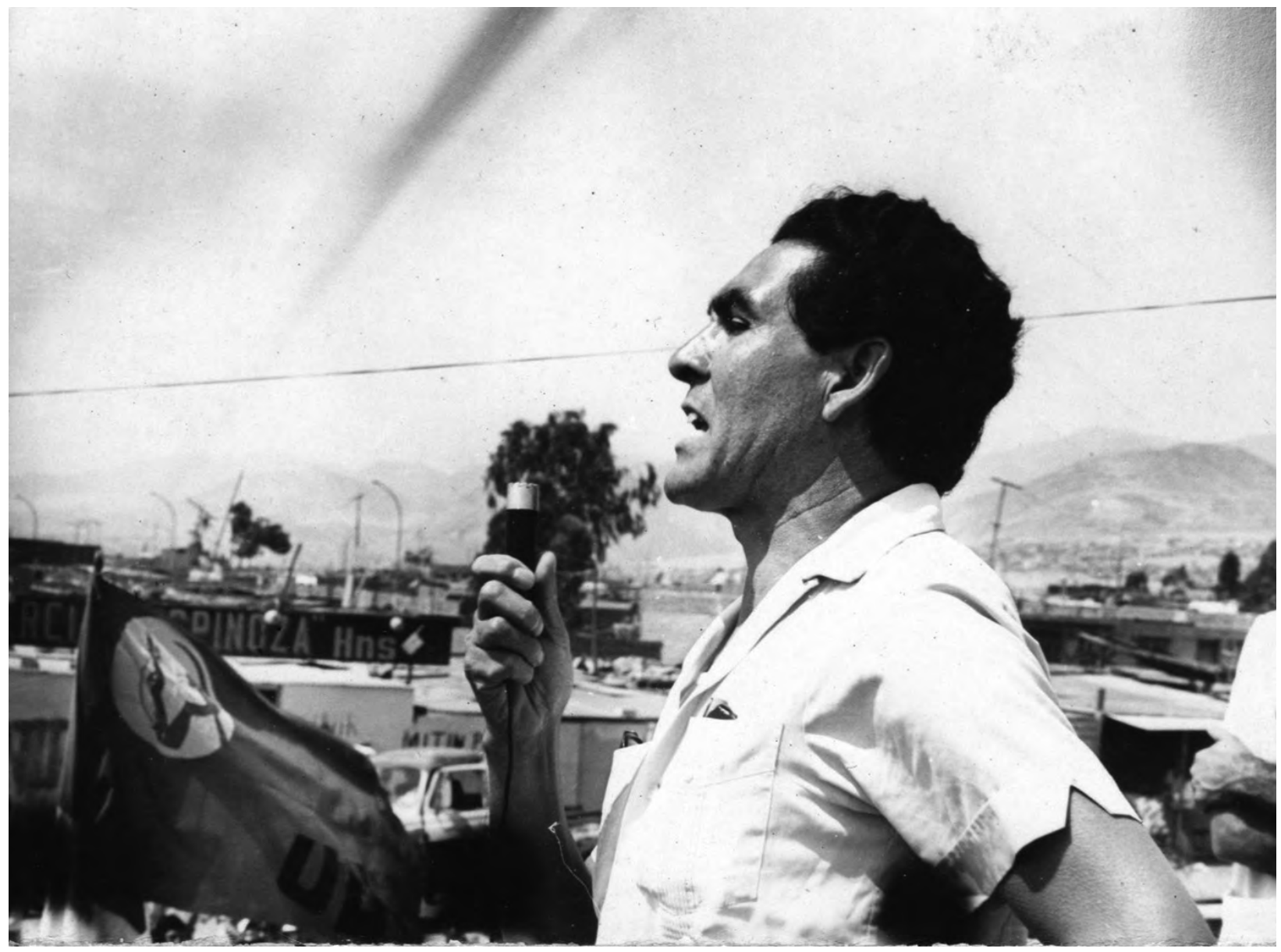

FОто 3. En un mitin político en Villa El Salvador, en diciembre de 1979. Aníbal pronunció un discurso a nombre del MRS, en compañía de los dirigentes de la CUAVES y en apoyo a la ARI en gestación. También asistieron los dirigentes del PRT, Patria Roja y VR.

«zorro» plateado del Apra se fue a Santiago de Chile. Días después, el 27 de octubre, ocurriría el golpe de Estado que derrocó al presidente Bustamante y Rivero. Contra aquel golpe militar acaudillado por su ministro de Gobierno, el general Odría, se desencadenaron protestas y movilizaciones populares y la revuelta estudiantil con la toma de la antigua Casona de San Marcos; la dictadura actuaría con brutalidad, haciendo que sus puertas fueran derribadas por las tanquetas, que fueran capturados y llevados a prisión numerosos estudiantes y entre ellos Quijano y sus compañeros apristas. Estuvieron prisioneros en la cárcel del Sexto de la Av. Bolivia pero liberados al poco tiempo, después nuevamente fueron capturados y mantenidos encarcelados por lo menos durante unos dos años; entre los presos políticos también habían comunistas del PCP, trotskistas y quizás algunos liberales radicales. Eran frecuentes los debates entre ellos. Había un común respeto y admiración por la
Unión Soviética, aún más, después de su aplastante victoria sobre las fuerzas nazistas de Hitler y, desde luego, al mismo tiempo, también había críticas a la burocratización del gobierno y el partido comunista soviético, pero los comunistas peruanos no los admitían de modo alguno y, a su vez, tampoco avanzaban un solo ápice, aparte de su ciega defensa y devoción por Stalin y el Estado de la URSS, en la actualización de sus conocimientos y reflexiones; no podían ni querían admitir lo que era notorio para muchos en la propia Europa y en América Latina, es decir, que el triunfo de la URSS en la contienda bélica y la conformación del campo socialista no significaban necesariamente ni el triunfo ni la continuidad de la revolución socialista y menos aún la construcción de la nueva sociedad socialista. Por otro lado, con cierta frecuencia, los presos políticos recibían por parte de familiares una serie de publicaciones pero no las de carácter político-partidario; a pedido de Aníbal, el tío 


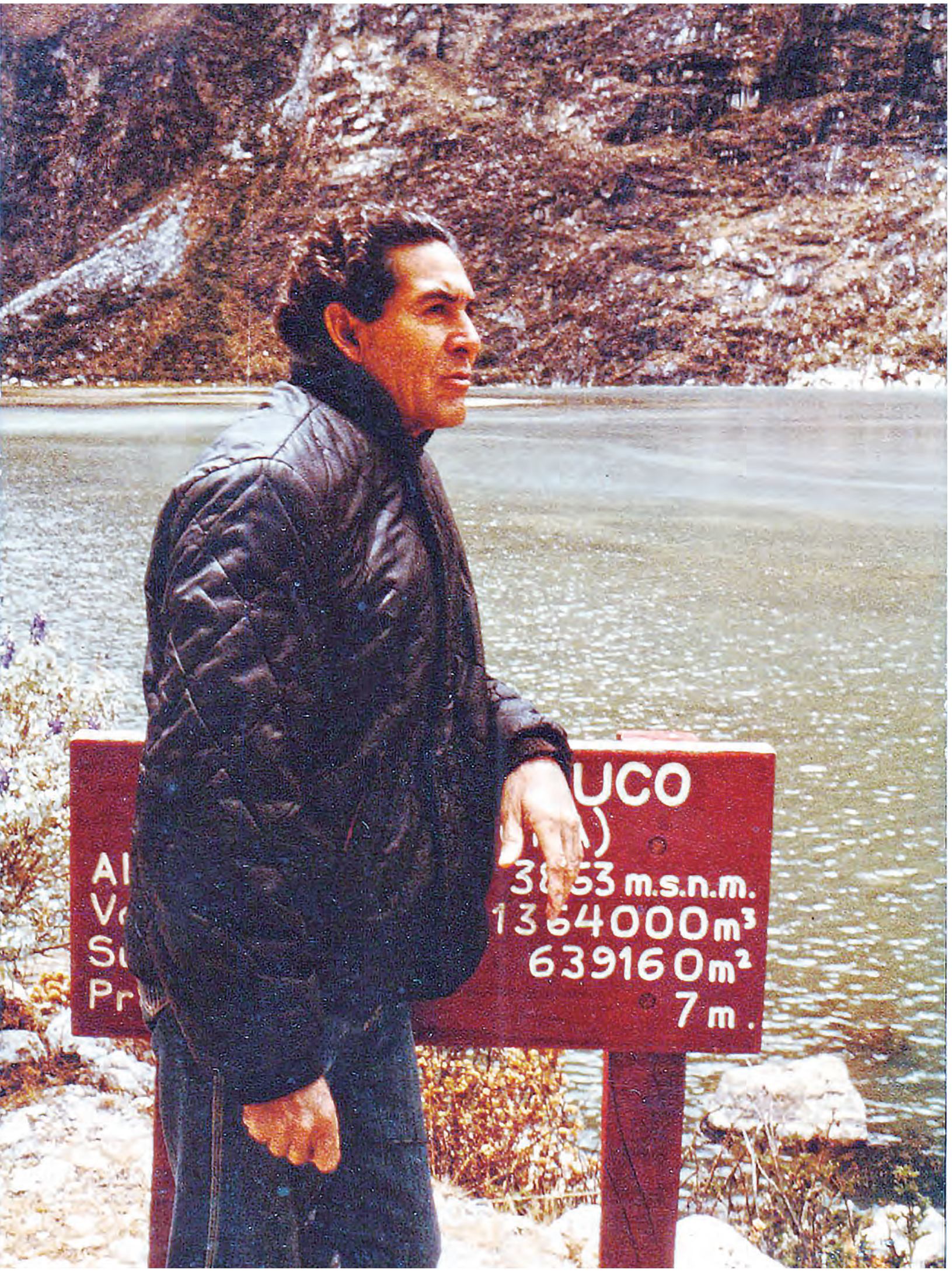

Fото 4. A orillas de las lagunas de Llanganuco, en un viaje de Yungay a Yanama. A mediados de los años 80 
policía y aprista le llevaba básicamente obras literarias entre novelas, cuentos y poemas. En el campo ideológico y político, algunos apristas, Aníbal entre ellos, transitaban en esas circunstancias del aprismo al socialismo revolucionario.

Al cabo de infinidad de gestiones, fundamentalmente de carácter familiar y amical, Aníbal fue liberado. Luego de una breve visita a su pueblo y familiares de Yanama y de una estancia de algunos meses en Chimbote, ayudando en los pequeños negocios de otro tío paterno, se reincorporó a San Marcos e hizo su traslado a la Facultad de Letras y Humanidades. Allí llevaría cursos de Historia, Arqueología y Antropología, Filosofía, Literatura, etc. contando con profesores del más alto nivel académico5. De otro lado, eran frecuentes los debates ideológicos y políticos en los viejos patios de San Marcos, el de Derecho en especial, entre estudiantes de las diversas tendencias de izquierda y uno de los problemas que los enfrentaban tenía que ver con el socialismo revolucionario y el destino de la URSS. Los críticos de esta potencia vencedora de la segunda Guerra Mundial, simplemente eran satanizados por los comunistas con una serie de adjetivos como «enemigos de la revolución», "traidores», «trotskistas», etc. Esta era la eterna letanía de los viejos y jóvenes militantes del PCP, es decir, con ellos no era posible debate teórico-ideológico alguno y siempre se mantuvieron irreductibles en esa posición ${ }^{6}$. Entre tanto, básicamente por cuenta propia, Aníbal estudiaba historia y teoría marxista; quizás hacia 1953 o 1954, le envía una larga carta a su padre hablándole de sus nuevos planes y proyectos y contándole que llevaba algunas semanas leyendo el Anti-dühring de Federico Engels, obra de crítica y debate en los campos de la filosofía, la economía política y el socialismo; a su vez, le decía que entre sus planes estaba la adquisición regular de lo mejor de la literatura marxista. En los comienzos de los años 60 pudimos conocer su biblioteca y ver que, además de novelas, cuentos y poemas, tenía las principales obras de Carlos Marx, Federico Engels, Vladimir Ilich Lenin, León Trotsky, etc. adquiridas

5 Entre dichos profesores, pueden ser mencionados Raúl Porras Barrenechea, Ella Dunbar Temple, Alberto Tauro del Pino, Jorge Basadre, Luis Valcárcel, Jorge Muelle, Jorge Puccinelli, Estuardo Núneez, José Russo Delgado, José Jiménez Borja, Arturo Jiménez Borja, Augusto Tamayo Vargas y otros. Por esos tiempos, venían al Perú numerosos arqueólogos y antropólogos de EE.UU. y Europa.

6 Mario Vargas Llosa, El pez en el agua. Madrid: Alfaguara, 1991. desde luego en la década anterior. También le contaba a su padre haber retornado a escribir sus poemas, luego de haber perdido un grueso manojo de ellos, provisoriamente titulado «Glauco Mar», en algunas de las varias incursiones policiales a su domicilio. Igualmente, le hablaba que luego de las frustrantes experiencias de dirección política partidaria vividas por los trabajadores y los pueblos del Perú en sus luchas por el poder, se encontraba afirmando sus convicciones acerca de la necesidad de construir un nuevo discurso revolucionario con la mayor autonomía intelectual posible.

Al mismo tiempo, cada vez más, Aníbal hacía parte activa de la Generación del 50, que aglutinaba a jóvenes universitarios o profesionales que se consideraban protagonistas de una nueva época después de ocurridos los graves desaciertos del Apra como dirección política hegemónica de las luchas por el poder en la década previa, la incompetencia política del presidente Bustamante y Rivero y su gobierno para conducir el país contra el poder oligárquico y por la afirmación de la senda democrática, su aislamiento y fácil entrega a los brazos de la derecha oligárquica que le hacía llegar demagógicos mensajes de apoyo, el golpe militar de 1948 del general Manuel Odría utilizando su condición de ministro de Gobierno - no tan remoto antecedente del reaccionario golpe militar de Pinochet en Chile de 1973 - la derrota de la "primavera democrática» y el retorno de una dictadura aún más feroz que las anteriores; al mismo tiempo, eran los tiempos de masivas y recurrentes migraciones del campo a la ciudad y la emergencia del problema urbano y las barriadas en expansión frente a un Estado crónicamente incapacitado para conducir los cambios económico-sociales como los que se presentaban ${ }^{7}$. Al término de la dictadura de Odría, muchos de los integrantes de la Generación del 50, especialmente escritores y poetas, comenzaron a publicar sus trabajos de creación. Manuel Scorza capitaneó una masiva difusión a nivel nacional de la producción

7 Entre algunos de los integrantes de los altos rangos de aquella generación, podemos mencionar a Julio Ramón Ribeyro, Alberto Escobar, Washington Delgado, Francisco Carrillo, Oswaldo Reynoso, Alejandro Romualdo, Pablo Macera, Carlos Araníbar, Juan Pablo Chang, Lobatón Milla, Ricardo Napurí, Alfonso Barrantes Lingán, Carlos Delgado Olivera, Hernando Aguirre Gamio, Ismael Frías Torrico, Abraham Zevallos, Eleodoro Vargas Vicuña, Javier Sologuren, Manuel Scorza, Mario Vargas Llosa, etc. 


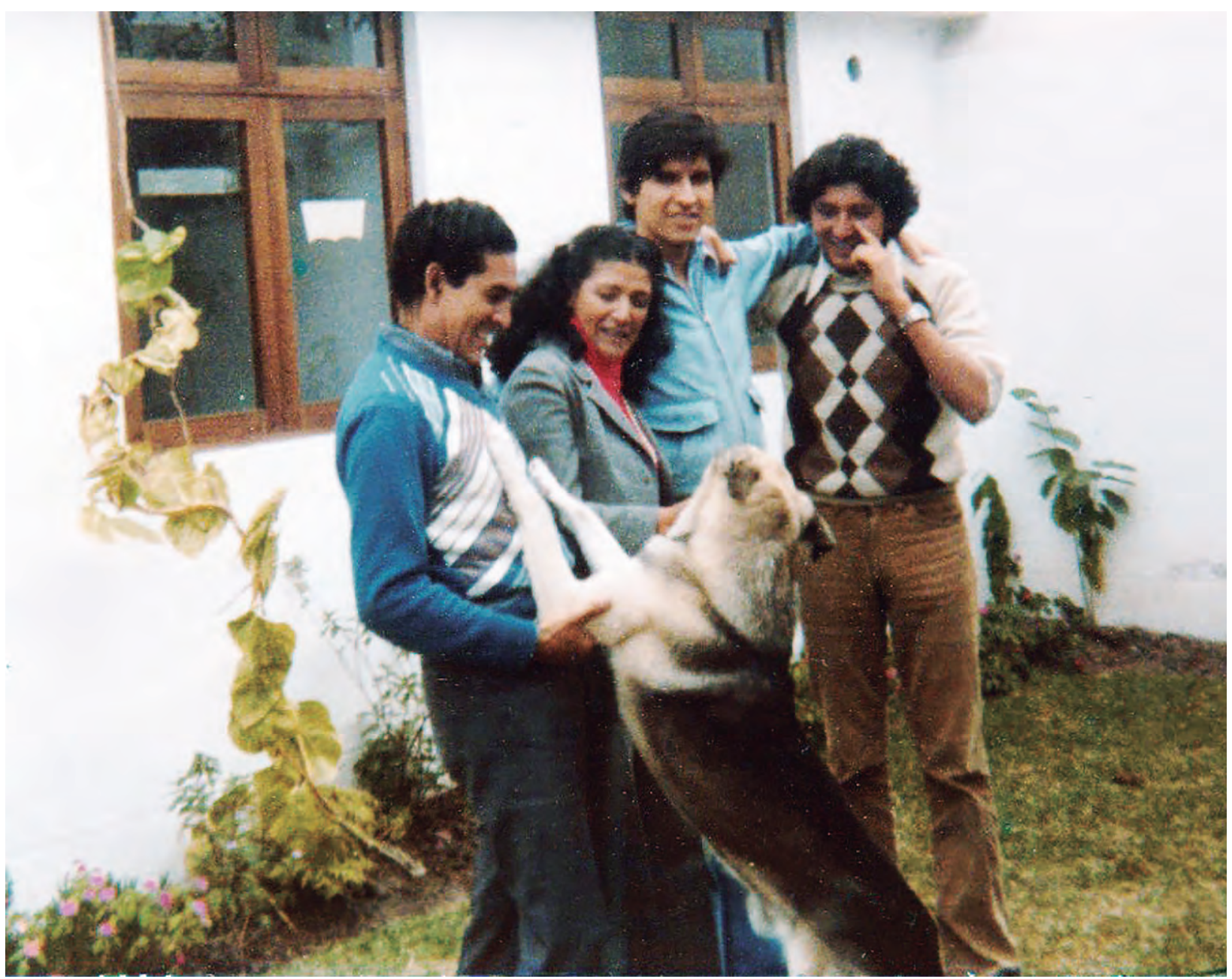

Fото 5. En su casa de San Borja, con su esposa Carmen y sus hijos Piero y Rodrigo, encariñados con el perro. A comienzos de los años 80.

intelectual correspondiente a las etapas previas de la historia peruana y, desde luego, de los propios de la Generación del 50. Así aparecieron desde 1956 las ediciones del Patronato del Libro Peruano cuya distribución y comercialización llegó a casi todas las provincias del país. El propio Aníbal participó en la publicación de cuentos y ensayos por él seleccionados. Quizás hacia 1958, hizo llegar a su padre don Marcial una colección de cuentos entre los que se encontraba el cuento "Gallinazos sin plumas» de Julio Ramón Ribeyro y otra colección que incluía «Ensayos escogidos de Manuel González Prada» por Augusto Salazar Bondy y, además, "Ensayos escogidos de José Carlos Mariátegui» y «Los mejores cuentos latinoamericanos", ambos por Aníbal Quijano. Además, en el transcurso de esos años, cultivaba una temprana y singular amistad con el escritor José María Arguedas y su esposa Celia Bustamante.
Por esa época, al culminar sus estudios en el Departamento de Historia de San Marcos y luego de dejar su trabajo de varios ańos en el Archivo General de la Nación, Aníbal se desempeñó como profesor en el colegio nacional Alfonso Ugarte, en el colegio Franco-Peruano y en la Universidad Enrique Guzmán y Valle de La Cantuta. Luego de su matrimonio con Carmen Pimentel Sevilla y del nacimiento de su primer hijo, en 1959 viajaría a Chile en condición de becado para hacer estudios de maestría en la FLACSO de Santiago de Chile. Hasta donde se sabe, luego de entrevistas y largas conversaciones con el entonces prestigioso sociólogo y peruanista francés François Bourricaud, este recomendó su viaje a Santiago de Chile donde permaneció por espacio de dos o tres años. Al retornar al Perú a comienzos de 1962, como Máster en Sociología, ingresó a trabajar como profesor y director del departamento de Ciencias Sociales 
de la Universidad Agraria de La Molina y, también, como profesor del departamento de Sociología en la Facultad de Letras de la UNMSM. En esta etapa sistematizó y profundizó sus estudios e investigaciones sobre la realidad peruana contemporánea y algunos de sus primeros resultados fueron «Proceso de cholificación en el Perú», "Los movimientos campesinos en el Perú y sus líderes», "Movimientos campesinos contemporáneos en América Latina», "Procesos de urbanización...», "Imperialismo y clases sociales en el Perú», «La crisis de los años 30 en el Perú», «La urbanización de la sociedad...», etc. Estos trabajos daban cuenta que había asumido con rigor su promesa de contribuir a la construcción de un pensamiento autónomo en función de las necesidades y urgencias de las luchas revolucionarias de los trabajadores y los pueblos. Una de las excepcionales visitas que Aníbal recibió en esos tiempos fue la del sociólogo europeo-norteamericano André Gunder Frank quien recorría América Latina llamando a estudiar y debatir problemas como "Capitalismo, desarrollo y subdesarrollo", "América Latina, lumpen desarrollo y lumpen burguesía». Luego, a fines de 1965, se vio obligado a tener que viajar nuevamente a Chile por razones de trabajo en un centro de estudios de historia latinoamericana dirigido por Rolando Mellafe y Álvaro Jara; después de un tiempo, ingresó a trabajar en la División de Asuntos Sociales de la CEPAL donde permaneció hasta comienzos de 1971 y en dicha etapa de su vida pudo viajar a distintas partes del mundo para dictar conferencias y participar en incontables debates sobre América Latina y los problemas internacionales; en esa época predominaban los debates de la teoría de la dependencia y Aníbal fue uno de sus protagonistas tanto como Fernando Henrique Cardoso, Enzo Faleto, Vania Bambirra, Theotonio Dos Santos, María Concepción Tavares y muchos otros como Gunder Frank que había decidido vivir en Chile; cada uno de ellos se destacó por sus numerosas y frecuentes publicaciones ${ }^{8}$. Retornó al Perú, habiendo escrito dos trabajos recientes acerca del gobierno revolucionario de las Fuerzas Armadas: «El golpe militar en el contexto peruano y latinoamericano" (con el seudónimo de Ramón Collar) y «Militarismo, neoimperialismo y nacionalismo en el Perú». Aquí le esperaban nuevos desafíos para las décadas siguientes y sabía que al tener que enfrentarlos tenía que vivir distintas experiencias de luchas y renovadas exigencias de carácter teórico a fin de aportar a la construcción de la dirección política del conjunto de dominados y explotados por el capital y su Estado. A lo largo de su vida se encaminó por ese rumbo. Lo pudo demostrar, por ejemplo, a través de su compromiso intelectual y vital con las luchas por la centralización y unificación clasista de los trabajadores, en los debates sobre la revolución socialista y la socialización del poder político, en la construcción histórica y teórica del problema de la colonialidad del poder / descolonialidad del poder, etc., cuestiones en pleno debate, hoy en día, a nivel latinoamericano e internacional.

Lima, 1 de octubre de 2018.

8 Acerca de los trabajos publicados por Aníbal Quijano en aquellos ańos de la CEPAL y en otras etapas de su trayectoria intelectual, ver de Danilo Assis Clímaco: Prólogo y Bibliografía de Aníbal Quijano en Aníbal Quijano, Cuestiones y horizontes. Antología esencial. Buenos Aires, CLACSO, abril de 2014. 